\title{
KARAKTERISASI ELEMEN IDEMPOTEN CENTRAL
}

\author{
HENRY W. M. PATTY ${ }^{1}$, ELVINUS RICHARD PERSULESSY ${ }^{2}$, RUDI WOLTER MATAKUPAN ${ }^{3}$ \\ ${ }^{1,2,3}$ Staf Jurusan Matematika FMIPA UNPATTI \\ Jl. Ir. M. Putuhena, Kampus Unpatti, Poka-Ambon \\ e-mail: henry_4t00@yahoo.com, richardelvinus@yahoo.com, rwmatakupan@yahoo.com
}

\begin{abstract}
ABSTRAK
Elemen idempoten $e$ dalam suatu ring $R$ dengan elemen satuan disebut idempotent central jika untuk sebarang $r \in R$ berlaku $e r=r e$. Selanjutnya dibentuk ring $e R e$ yang merupakan subring dengan elemen satuan $e$. Dimotivasi dari struktur ring $e R e$ akan diselidiki sifat-sifat dalam ring dan modul diantaranya, indecomposable, homomorfisma dan radikal Jacobson, dalam kaitannya dengan elemen idempotent central. Dalam tulisan ini akan dipelajari karakterisasi
\end{abstract}

Kata kunci: indecomposable, homomorfisma, radikal Jacobson, idempoten central

\section{PENDAHULUAN}

Dalam struktur ring $R$ yang komutatif, jika dipunyai suatu elemen idempoten $e \in R$ maka ring $R$ tersebut dapat didekomposisikan (decomposable) menjadi hasil kali langsung dari ring $R e$ dan $R(1-e)$. Dilain pihak, terdapat ring yang tidak dapat dinyatakan sebagai hasil kali langsung dari dua ring yang tak nol. Ring ini disebut ring yang tidak dapat didekomposisikan (indecomposable). Dalam ring yang indecomposable ini, hanya 0 dan 1 yang merupakan elemen idempoten atau sering disebut idempoten trivial.

Sebaliknya dalam teori ring nonkomutatif, elemen idempoten dikenal dengan sebutan idempoten central. Hal ini berarti suatu ring $R$ yang tak nol disebut indecomposable jika ring tersebut tidak memiliki elemen idempoten central yang nontrivial. Selanjutnya untuk memahami struktur ring indecomposable ini, diperlukan pengetahuan tentang karakteristik elemen idempoten central yang dalam perkembangannya lebih banyak berperan dalam teori ring nonkomutatif dibandingkan dalam teori ring komutatif. Oleh karena itu dalam tulisan ini akan dibahas karakteristik elemen idempoten khususnya elemen idempoten central.

\section{TINJAUAN PUSTAKA}

Untuk mempelajari karakteristik elemen idempoten central ini diperlukan beberapa pengetahuan dasar tentang ring dan modul diantaranya ideal maksimal, homomorfisma, radikal Jacobson dan jumlah langsung (direct sum) yang dikaji dari Malik (1997) dan Fuller (1992). Selanjutnya dalam bukunya yang berjudul $A$ first Course in Noncommutative Rings, Tsit Yuen Lam (1991) menjelaskan beberapa sifat elemen idempoten central dan peranannya dalam struktur ring dan modul. Ring yang dibicarakan dalam tulisan ini adalah ring dengan elemen satuan. Jadi, tidak harus komutatif terhadap operasi pergandaan. Berikut ini diberikan beberapa definisi dan sifat yang melandasi karakterisasi elemen idempoten central.

\section{Definisi 1}

Suatu elemen $e \in R$ disebut elemen idempoten jika $e^{2}=e$.

Selanjutnya diberikan beberapa sifat dalam ideal kanan $e R$ dan $(1-e) R$ dengan asumsi analog untuk ideal kiri $R e$ dan $R(1-e)$. 


\section{Proposisi 1.}

Misalkan $e \in R$ elemen idempoten dalam $R$. Suatu ideal kanan $e R$ dan $(1-e) R$ dapat dinyatakan sebagai berikut

$$
e R=\{e r \mid r \in R\} \text { dan }(1-e) R=\{(1-e) r \mid r \in R\}
$$

Selanjutnya didefinisikan hasil tambah langsung (direct sum) dari ideal kanan $e R$ dan $(1-e) R$ sebagai berikut.

\section{Definisi 2.}

Misalkan $e R$ dan $(1-e) R$ ideal kanan dalam $R$ maka $R$ disebut direct sum dari ideal kanan $e R$ dan $(1-e) R$, dinotasikan $R=e R \oplus(1-e) R, \quad$ jika $R=e R+(1-e) R$ dan $e R \cap(1-e) R=\{0\}$.

Berikut ini diberikan definisi dan beberapa sifat dari ideal kanan maksimal dalam suatu ring $R$ dengan asumsi bahwa definisi dan sifat-sifat tersebut juga berlaku untuk ideal kiri maksimal.

\section{Definisi 3.}

Ideal kanan $M \subseteq R$ disebut ideal kanan maksimal jika $M \neq R$ dan tidak terdapat suatu ideal kanan $I \subset R$ sedemikian sehingga $M \subset I \subset R$. Selanjutnya, suatu ideal kanan $N \subset R$ disebut ideal kanan minimal jika $N \neq\{0\}$ dan tidak terdapat ideal kanan $J \subset R$ sedemikan hingga $\{0\} \neq J \subset N \subset R$.

Berikut ini diberikan pengertian radikal Jacobson dari suatu ring dalam kaitannya dengan ideal kanan maksimal dengan asumsi yang analog untuk ideal kiri maksimal.

\section{Definisi 4.}

Radikal Jacobson dari suatu ring $R$ (dinotasikan $\operatorname{Jac}(R)$ ) adalah irisan dari semua ideal kanan maksimal dalam $R$. Jadi,

$$
\operatorname{Jac}(R)=\bigcap\{M \mid M \text { ideal kanan maksimal dalam } R\}
$$

Berdasarkan Definisi 3, dapat dipahami bahwa ideal kanan $M \subseteq R$ disebut ideal kanan maksimal jika terdapat suatu ideal kanan $I \subseteq R$ yang memenuhi sifat $M \subseteq I \subseteq R \quad$ maka berlaku $I=M$ atau $I=R$. Selanjutnya, suatu ideal $I \subseteq R$ disebut ideal sejati jika $I \neq R$.

Selain itu radikal Jacobson dari suatu ring $R$ dapat dipahami dengan bantuan elemen unit dalam ring tersebut, seperti yang termuat dalam sifat berikut ini.

Teorema 1. Jika $y \in \operatorname{Jac}(R)$ maka $1-x y$ merupakan unit kiri untuk setiap $x \in R$.

Bukti: Diambil sebarang $y \in \operatorname{Jac}(R)$. Akan ditunjukkan $1-x y$ merupakan unit kiri dalam $R$. Diandaikan terdapat $1-x y$ yang bukan unit kiri dalam $R$. Artinya $R .(1-x y) \subset R \quad$ dan $\quad R .(1-x y) \neq R$. Karena ideal
$R .(1-x y) \subset R$ termuat dalam suatu ideal maksimal $M \subset R$. Akibatnya, $1-x y \in M$ dan $y \in M$ sehingga diperoleh $1 \in M$. Timbul kontradiksi dengan $M$ sebagai ideal maksimal, maka $1-x y$ merupakan unit kiri dalam $R$.

\section{HASIL DAN PEMBAHASAN}

Dalam bagian ini akan dibahas beberapa sifat elemen idempoten central sebagai berikut.

\section{Karakterisasi Elemen Idempoten Central}

Misalkan $R$ ring dengan elemen satuan. Jika ideal $R e$ dan $(1-e) R$ berturut-turut merupakan ideal kanan yang dibangun oleh elemen idempoten $e$ dan $1-e$ maka ring $R$ dapat dinyatakan sebagai dekomposisi dari $e R$ dan $(1-e) R$, seperti yang dijelaskan dalam proposisi berikut ini.

\section{Proposisi 2.}

Misalkan $R$ ring dengan elemen satuan. Elemen $e$ dan $1-e$ idempoten di $R$, maka berlaku:

(1) $e R$ dan $(1-e) R$ ideal kanan dalam $R$.

(2) $\quad R=e R \oplus(1-e) R$.

\section{Bukti:}

(1) Diambil sebarang $e r_{1}, e r_{2} \in e R$ dan $s \in R$. Akan ditunjukkan $e R$ ideal kanan dalam $R$. Diperoleh, $e r_{1}-e r_{2}=e\left(r_{1}-r_{2}\right) \in e R$ dan $e r . s=e(r s) \in e R$.

Terbukti $e R$ merupakan ideal kanan dalam $R$. Analog untuk $(1-e) R$.

(2) Diambil sebarang $a \in R$ dan diketahui $e$ elemen idempoten dalam $R$. Akan ditunjukkan $R=e R \oplus(1-e) R$. Diperoleh

$$
a=e a+a-e a=e a+(1-e) a
$$

dengan $e a \in e R$ dan $(1-e) a \in(1-e) R$. Hal ini berarti $R=e R+(1-e) R$. Selanjutnya diambil sebarang $b \in e R \cap(1-e) R$ yang artinya $b=e c$ dan $b=(1-e) d$ untuk suatu $c, d \in R$. Jika digandakan dengan $e \in R$ akan diperoleh $e b=e^{2} c=e c=b$ dan $e b=e(1-e) d=\left(e-e^{2}\right) d=(e-e) d=0$. Dengan demikian $\quad b=e b=0 \quad$ atau $e R \cap(1-e) R=\{0\}$.

Terbukti $R=e R \oplus(1-e) R$.

Berdasarkan Proposisi 2 dapat dinyatakan bahwa, suatu ring $R$ juga merupakan jumlah langsung dari idealideal kiri dalam $R$ yang dibangun oleh elemen idempoten $e$ dan $1-e($ dinotasikan $R=R e \oplus R(1-e))$. Sedangkan untuk ring $R \neq 0$ yang tidak dapat dinyatakan sebagai jumlah langsung dari sebarang dua ideal yang tak nol disebut ring indecomposable. Ring tersebut hanya memiliki elemen idempoten yang trivial yaitu 0 dan 1 . 
Selanjutnya, jika $e$ elemen idempoten central maka ring $e R e=\{$ ere $\mid r \in R\}$ merupakan subring dengan elemen satuan $e$. Namun sebelumnya diberikan definisi elemen idempoten central sebagai berikut.

\section{Definisi 5.}

Suatu elemen idempoten $e \in R$ disebut central jika untuk sebarang $r \in R$ berlaku $e r=r e$. Himpunan semua elemen idempoten central dinotasikan dengan $C(R)$.

\section{Proposisi 3.}

Jika $R$ ring dengan elemen idempoten central $e$ maka $e R e=\{$ ere $\mid r \in R\}$ merupakan subring dengan elemen satuan $e$.

\section{Bukti:}

Diambil sebarang $x_{1}, x_{2} \in e R e$ dengan $x_{1}=e r_{1} e$ dan $x_{2}=e r_{2} e$, untuk suatu $r_{1}, r_{2} \in R$. Akan ditunjukkan $e R e$ merupakan subring dengan elemen satuan $e$.

(i) $x_{1}-x_{2}=e r_{1} e-e r_{2} e=e\left(r_{1}-r_{2}\right) e \in e R e$

(ii) $x_{1} \cdot x_{2}=\left(e r_{1} e\right)\left(e r_{2} e\right)=e r_{1} e^{2} r_{2} e=e\left(r_{1} e r_{2}\right) e=e\left(r_{1} r_{2}\right) e$

$$
\in e R e
$$

Dari (i) dan (ii) terbukti $e R e$ merupakan subring. Misalkan $e \in e R e$ dengan $e=e .1 . e$ maka untuk setiap $x \in e R$ e dengan $x=$ ere

diperoleh

$e x=e($ ere $)=e^{2}$ re $=$ ere $=x$

dan

$x e=($ ere $) e=e^{2} e^{2}=$ ere $=x$.

Terbukti $e$ R $e$ subring dengan elemen satuan $e$.

Berdasarkan Proposisi 3. maka suatu ring $e R e$ dan $f R f$ dapat dinyatakan sebagai berikut.

$$
\begin{aligned}
& \text { (i) } e R e=\{e r=r=r e \mid r \in R\} \quad \text { dan } \\
& \text { (ii) } f R f=\{f r=r=r f \mid r \in R\}
\end{aligned}
$$

dengan $e$ dan $f=1-e$ berturut-turut merupakan elemen idempoten central sekaligus merupakan elemen satuan. Selanjutnya, diberikan proposisi tentang elemen idempoten central yang ditinjau dari (1).

\section{Proposisi 4.}

Suatu elemen idempoten $e$ merupakan idempoten central ( $e \in C(R))$ jika dan hanya jika $e R f=f R e=\{0\}$.

Bukti: Diambil sebarang $r \in R$ dan diberikan $e, f \in C(R)$ dengan $f=1-e$. Akan ditunjukkan $e R f=f R e=\{0\}$. Diperoleh

erf $=e r(1-e)=e r-e r e=e r-e r=0$

dan

fre $=(1-e) r e=r e-e r e=r e-r e=0$.

Terbukti $e R f=\{0\}=f R e$.
Sebaliknya, diberikan $e R f=f R e=\{0\} . \quad$ Akan ditunjukkan untuk setiap $r \in R$ berlaku $e \in C(R)$ atau $e r-r e=0$. Jika $e r f=0$ dengan $f=1-e$ maka berlaku $\operatorname{er}(1-e)=0$ atau er-ere $=0$. Akibatnya, er $=$ ere. Selanjutnya, jika fre $=0$ maka berlaku $(1-e) r e=0$ atau re-ere $=0$. Akibatnya, re $=$ ere.

Terbukti, re $=$ ere $=e r$.

Dalam suatu ring $R$ yang memiliki sebarang elemen idempoten $e$ dan $e^{\prime}$, dapat ditentukan $\operatorname{Hom}_{R}\left(e R, e^{\prime} R\right)$ sebagai homomorfisma dari $e R$ ke $e^{\prime} R$. Berikut ini diberikan suatu isomorfisma antara $e R$ dan $e^{\prime} R$ dengan suatu ring $e^{\prime} R e$.

\section{Proposisi 5.}

Jika diberikan sebarang elemen idempoten $e$ dan $e^{\prime}$ dalam suatu ring $R$ dan $M_{R}$ modul kanan atas ring $R$ maka terdapat suatu isomorfisma grup aditif $\lambda: \operatorname{Hom}_{R}\left(e R, M_{R}\right) \rightarrow M_{R} e$.

Bukti: Diberikan suatu homomorfisma modul, $\theta: e R \rightarrow M_{R}$. Untuk setiap $r \in R$ dengan $r \neq e$ diperoleh $\theta(e r)=m$ sedangkan untuk $r=e$ juga diperoleh $\theta(e e)=m$. Karena $e$ elemen idempoten maka $\theta(e)=m$ sehingga berlaku $\theta(e r)=m=\theta(e)$. Selanjutnya, didefinisikan suatu pemetaan $\lambda: \operatorname{Hom}_{R}\left(e R, M_{R}\right) \rightarrow M_{R} e$ dengan $\lambda(\theta)=m e$, untuk setiap $m \in M_{R}$. Jika $\theta(e)=m$ maka diperoleh $m e=\theta(e) e=\theta\left(e^{2}\right)=\theta(e)=m$ atau dengan kata lain $m=m e \in M_{R} e$, sehingga berlaku $\lambda(\theta)=m e=m=\theta(e)$.

Akan ditunjukkan $\lambda$ isomorfisma grup aditif atau $\operatorname{Hom}_{R}\left(e R, M_{R}\right) \cong M_{R} e$.

(i) Akan ditunjukkan $\lambda$ terdefinisi.

Diambil sebarang $\theta_{1}, \theta_{2} \in \operatorname{Hom}_{R}\left(e R, M_{R}\right)$ dengan $\theta_{1}=\theta_{2}$. Akan ditunjukkan $\lambda\left(\theta_{1}\right)=\lambda\left(\theta_{2}\right)$. Jika $\theta_{1}=\theta_{2}$ atau dengan kata lain $\theta_{1}-\theta_{2}=0$ maka untuk suatu elemen idempoten $e \in R$ diperoleh $\left(\theta_{1}-\theta_{2}\right) e=0$. Selanjutnya, karena $\theta$ suatu homomorfisma modul maka berlaku $\theta_{1}(e)-\theta_{2}(e)=0$ atau $\theta_{1}(e)=\theta_{2}(e)$. Mengingat definisi $\theta(e)=\lambda(\theta)$ maka untuk $\theta_{1}(e)=\theta_{2}(e)$ diperoleh $\lambda\left(\theta_{1}\right)=\lambda\left(\theta_{2}\right)$. Terbukti, $\lambda$ terdefinisi.

(ii) Akan ditunjukkan $\lambda$ homomorfisma grup.

Diambil sebarang $\theta_{1}, \theta_{2} \in \operatorname{Hom}_{R}\left(e R, M_{R}\right)$.

Diperoleh

$$
\begin{aligned}
\lambda\left(\theta_{1}+\theta_{2}\right)= & \left(\theta_{1}+\theta_{2}\right) e=\theta_{1}(e)+\theta_{2}(e) \\
= & \lambda\left(\theta_{1}\right)+\lambda\left(\theta_{2}\right) .
\end{aligned}
$$

Terbukti, $\lambda$ homomorfisma grup.

(iii) Akan ditunjukkan $\lambda$ injektif. 
Diambil sebarang $\lambda\left(\theta_{1}\right), \lambda\left(\theta_{2}\right) \in M_{R} e$ dengan $\lambda\left(\theta_{1}\right)=\lambda\left(\theta_{2}\right)$. Akan ditunjukkan $\theta_{1}=\theta_{2}$. Karena $\lambda\left(\theta_{1}\right)=\lambda\left(\theta_{2}\right)$ atau $\lambda\left(\theta_{1}\right)-\lambda\left(\theta_{2}\right)=0$ maka untuk suatu homomorfisma $\lambda$ diperoleh $\lambda\left(\theta_{1}-\theta_{2}\right)=0$. Selanjutnya, karena didefinisikan $\lambda(\theta)=\theta(e)$ maka untuk $\lambda\left(\theta_{1}-\theta_{2}\right)=0$ diperoleh

$\left(\theta_{1}-\theta_{2}\right) e=0$ atau $\theta_{1}(e)-\theta_{2}(e)=0$. Akibatnya, $\theta_{1}(e)=\theta_{2}(e)$ atau $\theta_{1}=\theta_{2}$. Terbukti, $\lambda$ injektif.

(iv) Akan ditunjukkan $\lambda$ surjektif.

Diambil sebarang $\theta(e) \in M_{R} e$. Akan ditunjukkan terdapat $\theta \in \operatorname{Hom}_{R}\left(e R, M_{R}\right) \quad$ sehingga berlaku $\lambda(\theta)=\theta(e)$. Karena $\theta(e)=m=m e=\lambda(\theta)$ maka akan selalu ditemukan $\theta \in \operatorname{Hom}_{R}\left(e R, M_{R}\right)$ sehingga $\lambda(\theta)=\theta(e)$. Terbukti, $\lambda$ surjektif.

Berdasarkan bukti (i)-(iv) terbukti bahwa

$$
\operatorname{Hom}_{R}\left(e R, M_{R}\right) \cong M_{R} e
$$

Berdasarkan Proposisi 5. diperoleh suatu akibat sebagai berikut.

\section{Akibat 1.}

Jika diberikan sebarang elemen idempoten $e$ dan $e^{\prime}$ dalam suatu ring $R$ maka $\operatorname{Hom}_{R}\left(e R, e^{\prime} R\right) \cong e^{\prime} R e$.

Bukti: Pada Proposisi 5 telah dibuktikan bahwa terdapat suatu isomorfisma grup aditif $\lambda: \operatorname{Hom}_{R}\left(e R, M_{R}\right) \rightarrow M_{R} e$ atau $\operatorname{Hom}_{R}\left(e R, M_{R}\right) \cong M_{R} e$. Dengan asumsi $M_{R}=e^{\prime} R$, maka diperoleh $\operatorname{Hom}_{R}\left(e R, e^{\prime} R\right) \cong e^{\prime} R e$.

Dari Akibat 1 diperoleh suatu akibat sebagai berikut.

\section{Akibat 2.}

Untuk suatu idempoten $e \in R$ terdapat suatu isomorfisma ring, $\operatorname{End}_{R}(e R) \cong e R e$.

Bukti: Diambil sebarang idempoten $e$ dan $e^{\prime}$ dengan $e=e^{\prime}$. Akan ditunjukkan $\operatorname{End}_{R}(e R) \cong e R e$. Berdasarkan Akibat $1 \operatorname{Hom}_{R}\left(e R, e^{\prime} R\right) \cong e^{\prime} R e$. Jika diasumsikan elemen idempoten $e=e^{\prime}$ maka diperoleh

$$
\operatorname{End}_{R}(e R)=\operatorname{Hom}_{R}(e R, e R) \cong e R e .
$$

Selanjutnya untuk suatu pemetaan $\theta: e R \rightarrow e R$ dengan definisi $\theta(e r)=e r, \forall r \in R$ serta mengingat Proposisi 5 yaitu $\theta(e r)=m=m e$ maka untuk suatu pemetaan $\lambda: \operatorname{Hom}(e R, e R) \rightarrow e R e$ diperoleh

$$
\lambda(\theta)=\text { ere }=\theta(\text { er }) e=m e=m .
$$

Dapat disimpulkan $m \in e R e$ yang artinya $m e=m=e m$. Akan dibuktikan $\lambda$ homomorfisma ring. Diambil sebarang $\theta, \theta^{\prime} \in \operatorname{End}_{R}(e R)$ maka diperoleh:

(i) $\lambda\left(\theta+\theta^{\prime}\right)=\left(\theta+\theta^{\prime}\right) e=\theta(e)+\theta^{\prime}(e)=\lambda(\theta)+\lambda\left(\theta^{\prime}\right)$

(ii) $\lambda\left(\theta^{\prime} \theta\right)=\theta^{\prime} \theta(e)=\theta^{\prime}(m)=\theta^{\prime}(e m)=\theta^{\prime}(e) m$

$$
=\lambda\left(\theta^{\prime}\right) \lambda(\theta)
$$

Berikut ini didefinisikan elemen idempoten yang saling ortogonal dan diberikan beberapa sifat indecomposable dalam ring.

\section{Definisi 6.}

Dua elemen idempoten $\alpha, \beta \in R$ dikatakan saling ortogonal jika $\alpha \beta=\beta \alpha=0$.

\section{Definisi 7.}

Suatu ring $R$ disebut indecomposable jika ring tersebut tidak memiliki elemen idempoten central yang nontrivial atau dengan kata lain hanya 0 dan 1 yang merupakan elemen idempoten central dalam $R$.

Dari sifat ring indecomposable, idempoten central dan idempoten ortogonal, dapat didefinisikan elemen idempoten yang primitif, namun sebelumnya diberikan suatu proposisi yang mendasari pendefinisian tersebut.

\section{Proposisi 7.}

Untuk sebarang idempoten $e \in R$ yang tidak nol, maka beberapa pernyataan berikut ini ekuivalen.

1. $\quad e R$ indecomposable sebagai $R$-modul kanan.

$R e$ indecomposable sebagai $R$-modul kiri.

2. Ring $e R e$ tidak memiliki idempoten yang non trivial.

3. Elemen $e$ tidak dapat didekomposisikan ke dalam bentuk $\alpha+\beta$ dengan $\alpha, \beta$ adalah idempoten tidak nol yang saling ortogonal.

\section{Bukti:}

$(1) \Leftrightarrow(2)$ Diketahui $e R$ indecomposable sebagai $R$ modul kanan. Akan ditunjukkan ring $e R e$ tidak memiliki idempoten yang nontrivial. Berdasarkan Akibat $2 \operatorname{End}_{R}(e R) \cong e R e$ maka ring $e R e$ juga indecomposable dengan kata lain ring $e R e$ tidak memiliki idempoten yang nontrivial. Dengan asumsi yang sama dibuktikan untuk pernyataan

$R e$ indecomposable sebagai $R$-modul kiri.

$(2) \Rightarrow(3)$ Dibuktikan dengan kontradiksi. Andaikan $e=\alpha+\beta$ dengan $\alpha$ dan $\beta$ idempoten tak nol yang saling ortogonal maka diperoleh $e \alpha=(\alpha+\beta) \alpha=\alpha^{2}+\beta \alpha=\alpha+0=\alpha$ dan $\alpha e=\alpha(\alpha+\beta)=\alpha^{2}+\alpha \beta=\alpha+0=\alpha$.

Diperoleh $\alpha \in e$ Re dan $\alpha \neq 0$ maka kontradiksi dengan (2) karena $e R e$ memuat idempoten yang nontrivial. Pengandaian diingkari, terbukti $e \neq \alpha+\beta$ dengan dengan $\alpha$ dan $\beta$ idempoten tak nol yang saling ortogonal.

(3) $\Rightarrow(2)$ Dibuktikan dengan kontradiksi. Diandaikan ring $e R e$ memiliki idempoten $\alpha$ yang nontrivial sehingga untuk suatu komplemen idempoten dari $\alpha$ yaitu $\beta=e-\alpha$ dengan 
$\beta \in e R e$, akan dipunyai suatu dekomposisi dari idempoten yang ortogonal yaitu $e=\alpha+\beta$. Akibatnya timbul kontradiksi dengan pernyataan (3), sehingga ring $e R e$ tidak mempunyai elemen idempoten yang nontrivial.

Berdasarkan Proposisi 7 didefinisikan suatu idempoten primitif sebagai berikut.

\section{Definisi 8.}

Suatu elemen idempoten $e \neq 0$ disebut idempoten primitif dari $R$, jika memenuhi salah satu dari kondisi berikut ini

1. $\quad R$ indecomposable sebagai $R$-modul kanan sedangkan $R e$ indecomposable sebagai $R$-modul kiri.

2. Ring $e R e$ tidak memiliki idempoten yang non trivial.

3. Elemen $e$ tidak dapat didekomposisikan ke dalam bentuk $\alpha+\beta$ dengan $\alpha, \beta$ adalah idempoten tak nol yang saling ortogonal.

Selanjutnya, struktur Jac $(e R e)$ dan $\bar{e} \bar{R} \bar{e}$ dapat dipahami dengan memanfaatkan teorema homomorfisma ring

\section{Teorema 1.}

Diberikan suatu elemen idempotent $e$ dalam $R$ dan $J=\operatorname{Jac}(R)$. Diperoleh $\operatorname{Jac}(e R e)=J \cap(e R e)=e J e$ dan $e$ Re/Jac $(e R e) \cong \bar{e} \bar{R} \bar{e}$.

Bukti: Diberikan elemen idempoten $e \in R$ dan $J=\operatorname{Jac}(R)$.

Akan ditunjukkan:

1. $\operatorname{Jac}(e R e)=J \cap(e R e)=e J e$

2. $e$ Re/Jac $(e R e) \cong \bar{e} \bar{R} \bar{e}$

1. Akan ditunjukkan $J a c(e R e)=J \cap(e R e)=e J e$. Dibuktikan dengan beberapa tahapan sebagai berikut:

(i) $r \in J a c(e R e) \Rightarrow r \in J$,

(ii) $r \in J \cap(e R e) \Rightarrow r \in e J e$,

(iii) $r \in e J e \Rightarrow r \in J a c(e R e)$

Pembuktian seperti berikut:

(i) Diambil sebarang $\quad r \in \operatorname{Jac}(e R e)$. Akan ditunjukkan $r \in J$. Berdasarkan Teorema 1 jika $r \in J=J a c(R)$ maka $1-y r$ unit dalam $R$, untuk setiap $y \in R$. Dengan asumsi yang sama maka untuk setiap $r \in J a c(e R e)$ dan $y \in e R e$ berlaku $e$-eye.r yang merupakan unit dalam $e R e$. Artinya untuk suatu $b \in e R e$ berlaku $b(e-e y e . r)=e, \quad$ akibatnya be $(1-y e . r)=e$. Karena $b \in e R e$ maka $b e=b=e b$ sehingga berlaku $b(1-y e r)=e$. Mengingat $y \in e R e$ maka diperoleh $b(1-y r)=e$. Di lain pihak, jika digandakan dengan $y r$ dari ruas kiri pada $b(1-y r)=e$ diperoleh $y r b(1-y r)=y r e=y r$ akibatnya $y r b-y r b . y r=y r$. Diberikan

$$
(1+y r b),(1-y r) \in R
$$

maka berlaku

$$
\begin{aligned}
(1+y r b)(1-y r) & =1(1-y r)+y r b(1-y r) \\
& =1-y r+y r=1 .
\end{aligned}
$$

Terbukti bahwa terdapat $1+y r b \in R$ sehingga berlaku $(1+y r b)(1-y r)=1$ atau dengan kata lain $1-y r$ unit dalam $R$.

(ii) Diambil sebarang $r \in J \cap e R e$. Akan ditunjukkan $r \in e J e$. Jika $r \in J \cap e R e$ yang artinya $r \in J$ dan $r \in e$ Re maka berlaku $r=e r e$. Sedangkan di lain pihak telah diketahui bahwa $r \in J$ dan mengingat bahwa $J \subseteq R$ maka diperoleh $r=e r e \in e J e$.

(iii) Diambil sebarang $r \in e J e \subseteq J$. Akan ditunjukkan $\quad r \in J a c(e R e)$. Berdasarkan Teorema 1 yaitu untuk setiap $y \in e R e$ maka $e-y r$ merupakan unit dalam $e R e$. Di lain pihak karena $r \in e J e \subseteq J=J a c(R)$ maka 1-yr merupakan unit dalam $R$, yang artinya terdapat suatu $x \in R$ sehingga berlaku $x(1-y r)=1$. Diperoleh $e=e \cdot 1 \cdot e=\operatorname{ex}(1-y r) e$ $=\operatorname{ex}(e-y r e)=e x(e-y r)=\operatorname{ex}\left(e^{2}-e y r\right)$ $=\operatorname{exe}(e-y r)$.

Dengan kata lain exe $\in e R e$ adalah invers kiri dari $e-y r$ atau $e-y r$ unit di $e R e$.

2. Akan ditunjukkan $e R e / \operatorname{Jac}(e R e) \cong \bar{e} \bar{R} \bar{e}$. Diberikan suatu pemetaan $\delta: e R e \rightarrow \bar{e} \bar{R} \bar{e}$ yang terdefinisi dengan $\delta($ ere $)=\bar{e} \bar{r} \bar{e}$. Suatu pemetaan $\delta$ merupakan homomorfisma ring dari $e R e$ ke $\bar{e} \bar{R} \bar{e}$, yakni untuk sebarang $e r_{1} e, e r_{2} e \in e R e$ diperoleh :

$$
\begin{aligned}
& \delta\left(e r_{1} e+e r_{2} e\right)=\delta\left(e\left(r_{1}+r_{2}\right) e\right)=\bar{e}\left(\overline{r_{1}+r_{2}}\right) \bar{e} \\
& =\bar{e}\left(\bar{r}_{1}+\bar{r}_{2}\right) \bar{e}=\bar{e} \overline{r_{1}} \bar{e}+\bar{e} \bar{r}_{2} \bar{e} \\
& =\delta\left(e r_{1} e\right)+\delta\left(e r_{2} e\right) \\
& =\delta\left(e r_{1} r_{2} e\right)=\bar{e}\left(\overline{r_{1} \cdot r_{2}}\right) \bar{e}=\bar{e}\left(\bar{r}_{1} \cdot \bar{r}_{2}\right) \bar{e} \\
& =\bar{e} \bar{r}_{1} \bar{e} \cdot \bar{e} \bar{r}_{2} \bar{e}=\delta\left(e r_{1} e\right) \cdot \delta\left(e r_{2} e\right)
\end{aligned}
$$

Di lain pihak $\delta: e R e \rightarrow \bar{e} \bar{R} \bar{e}$ juga merupakan suatu epimorfisma karena untuk setiap $\bar{e} \bar{r} \bar{e} \in \bar{e} \bar{R} \bar{e}$ dengan masing-masing $\bar{e}$ dan $\bar{r}$ adalah bayangan dari $e$ dan $r$ sehingga berlaku

$$
\bar{e} \bar{r} \bar{e}=(e+J)(r+J)(e+J)=\text { ere }+J \in \bar{e} \bar{R} \bar{e} .
$$

Hal ini berarti untuk setiap $\bar{e} \bar{r} \bar{e} \in \bar{e} \bar{R} \bar{e}$ dapat ditemukan ere $\in e R e$ sehingga berlaku 
$\delta($ ere $)=\bar{e} \bar{r} \bar{e}$. Diperoleh, untuk setiap ere $\in e R e$ berlaku

$$
\operatorname{Im}(\delta)=\{\bar{e} \bar{r} \bar{e} \in \bar{e} \bar{R} \bar{e} \mid \delta(\text { ere })=\bar{e} \bar{r} \bar{e}\}=\bar{e} \bar{R} \bar{e}
$$

dan

$$
\begin{aligned}
\operatorname{Ker}(\delta) & =\{\text { ere } \in \text { eRe } \mid \delta(\text { ere })=\overline{0}\} \\
& =\{\text { ere } \in e R e \mid \bar{e} \bar{r} \bar{e}=\overline{0}\} \\
& =\{\text { ere } \in e R e \mid \text { er } e+J=0+J\} .
\end{aligned}
$$

Jika $e R e \in J$ dan ere $\in e R e$ maka ere $\in J \cap e R e$. Selanjutnya, mengingat bukti (1.i) dan (1.ii), jika $J \cap(e R e)=e J e$ maka ere $\in e J e$ dan $\operatorname{Ker}(\delta)$ $=e J e=\operatorname{rad}(e R e)$. Dengan mengingat teorema utama homomorfisma ring diperoleh

$$
e \operatorname{Re} / \operatorname{Ker}(\delta) \cong \operatorname{Im}(\delta) \text {. }
$$

Terbukti $e$ Re/Jac $(e R e) \cong \bar{e} \bar{R} \bar{e}$

Berikut ini diberikan proposisi yang mendasari definisi isomorfisma antara dua elemen idempoten dalam suatu ring $R$.

\section{Proposisi 8.}

Diberikan elemen idempoten $e, f \in R$, maka pernyataanpernyataan berikut ini ekuivalen

1. $\quad e R \cong f R$ sebagai $R$-modul kanan.

$R e \cong R f$ sebagai $R$-modul kiri.

2. Terdapat elemen $a \in e R f$ dan $b \in f R e$ sedemikian sehingga $e=a b$ dan $f=b a$.

3. Terdapat elemen $a, b \in R$ sedemikian sehingga $e=a b$ dan $f=b a$.

\section{Bukti:}

$1 \Rightarrow 2$ Diberikan $R e \cong R f$ sebagai modul kanan atas $R$.

Akan ditunjukkan $e=a b$ dan $f=b a$.

Berdasarkan Proposisi 5, untuk sebarang elemen idempoten $e$ dan $f$, dengan $e R \cong f R$ dapat ditemukan suatu isomorfisma $\theta: e R \rightarrow f R$ atau $\operatorname{Hom}_{R}(e R, f R) \cong f R e \quad$ dengan definisi $\theta(e)=b \in f R e$.Sebaliknya untuk suatu pemetaan invers $\theta^{-1}: f R \rightarrow e R$ atau $\operatorname{Hom}_{R}(f R, e R) \cong e R f$ didefinisikan $\theta^{-1}(f)=a \in e R f$. Karena $b \in f R e$ dengan $f, e$ yang juga merupakan elemen satuan maka berlaku $f b=b=b e$ dan untuk setiap $a \in e R f$ berlaku $e a=a=a f$ diperoleh

$$
\begin{aligned}
& \left(\theta^{-1} \theta\right)(e)=\theta^{-1}(\theta(e))=\theta^{-1}(b)=\theta^{-1}(f b) \\
& =\theta^{-1}(f) b=a b, \\
& \theta\left(\theta^{-1}(f)\right)=\theta(a)=\theta(e a)=\theta(e) a=b a \text {. }
\end{aligned}
$$

Dari hasil komposisi, elemen $e$ dipetakan ke $a b$ dan elemen $f$ dipetakan ke $b a$. Karena $\theta^{-1} \theta=1$ dan $\theta \theta^{-1}=1$ maka terbukti $e=a b$ dan $f=b a$.
Bukti $R e \cong R f$ sebagai $R$-modul kiri dikerjakan secara analog dengan asumsi $R e \cong R f$ sebagai modul kiri atas $R$.

$2 \Rightarrow 3$ Pernyataan 2 dan 3 adalah pernyataan yang trivial.

$3 \Rightarrow 1$ Diberikan $a, b \in R$ dengan $e=a b$ dan $f=b a$. Akan ditunjukkan $e R \cong f R$ sebagai modul kanan atas $R$.

Dipunyai $\quad b e=b(a b)=(b a) b=f b \in f R \quad$ dan $a f=a(b a)=(a b) a=e a \in e R$.

Selanjutnya, didefinisikan $\theta: e R \rightarrow f R$ dengan $\theta(e)=b \in f R$ sehingga untuk setiap $x \in e R$ diperoleh $\theta(x)=\theta(e x)=\theta(e) x=b x \in f R$.

Didefinisikan juga $\theta^{-1}: f R \rightarrow e R$ dengan $\theta^{-1}(f)=a \in e R$ sehingga untuk setiap $y \in R$ berlaku $\theta^{-1}(y)=\theta^{-1}(f y)=\theta^{-1}(f) y=a y \in e R$. Karena $\theta(e)=b=f b=b e$ dan $\theta^{-1}(f)=a=e a=a f$ diperoleh $\theta^{-1} \theta(e)=\theta^{-1}(\theta(e))=\theta^{-1}(b e)$ $=a(b e)=(a b) e=e e=e^{2}=e$ $\operatorname{dan} \theta \theta^{-1}(f)=\theta\left(\theta^{-1}(f)\right)=\theta(a f)=b(a f)$ $=(b a) f=f f=f^{2}=f$.

Karena $\theta \theta^{-1}=1$ dan $\theta^{-1} \theta=1$, terbukti $e R \cong f R$.

Berdasarkan Proposisi 8 dapat didefinisikan isomorfisma antara dua elemen idempoten dalam $R$ sebagai berikut.

\section{Definisi 9.}

Elemen idempoten $e$ dikatakan saling isomorfisma dengan idempoten $f$ (dinotasikan $e \cong f$ ) jika memenuhi salah satu dari kondisi berikut ini.

1. $e R \cong f R$ sebagai modul kanan atas $R$ sedangkan $R e \cong R f$ sebagai modul kiri atas $R$.

2. Terdapat elemen $a \in e R f$ dan $b \in f R e$ sedemikian sehingga $e=a b$ dan $f=b a$.

3. Terdapat elemen $a, b \in R$ sedemikian sehingga $e=a b$ dan $f=b a$.

\section{KESIMPULAN}

Berdasarkan pembahasan maka dapat disimpulkan bahwa beberapa karakteristik dari elemen idempotent central adalah sebagai berikut:

1. Syarat perlu dan cukup suatu elemen idempoten $e$ merupakan idempoten central adalah

$$
e R f=f R e=\{0\} \text {. }
$$


2. Jika diberikan sebarang elemen idempoten $e$ dan $e^{\prime}$ dalam suatu ring $R$ dan $M_{R}$ modul kanan atas $\operatorname{ring} R$ maka terdapat suatu isomorfisma grup aditif

$$
\lambda: \operatorname{Hom}_{R}\left(e R, M_{R}\right) \rightarrow M_{R} e .
$$

4. Untuk sebarang idempoten $e \in R$ yang tidak nol, maka beberapa pernyataan berikut ini ekuivalen yaitu $e R(R e)$ indecomposable sebagai $R$-modul kanan $(R$ modul kiri), ring $e R e$ tidak memiliki idempoten yang non trivial, elemen $e$ tidak dapat didekomposisikan ke dalam bentuk $\alpha+\beta$ dengan $\alpha, \beta$ adalah idempoten tidak nol yang saling ortogonal.

5. Jika diberikan suatu elemen idempoten $e$ dalam $R$ dan $J=\operatorname{Jac}(R)$ maka diperoleh $\operatorname{Jac}(e R e)=J \cap(e R e)$ $=e J e$ dan $e$ Re/Jac $(e R e) \cong \bar{e} \bar{R} \bar{e}$.

6. Untuk sebarang elemen idempoten $e, f \in K$, maka beberapa pernyataan berikut ini ekuivalen yaitu: $e R \cong f R(R e \cong R f)$ sebagai $R$-modul kanan ( $R$-modul kiri), terdapat elemen $a \in e R f$ dan $b \in f R e$ sedemikian sehingga $e=a b$ dan $f=b a$, terdapat elemen $a, b \in R$ sehingga $e=a b$ dan $f=b a$.

\section{DAFTAR PUSTAKA}

Anderson, W. dan Fuller, K., 1992, Ring and Categories of Modules, Springer Verlag, New York.

Lam, T.Y., 1991, A First Course in Noncommutative Rings, Springer Verlag, New York.

Malik, D.S., Mordeson, J. M., dan Sen, M. K., 1997, Fundamentals of Abstract Algebra, The McGrawHill Companies, Inc, NewYork. 